\title{
Peritonitis focal como forma de presentación clínica de una listeriosis
}

\author{
J. SÁNCHEZ BEORLEGUI, S. GARCÍA SÁNCHEZ \\ Servicios de Cirugía General y del Aparato Digestivo. Hospital Comarcal de Jaca. \\ ${ }^{1}$ Anatomía Patológica. Hospital Royo Villanova. Zaragoza
}

FOCAL PERITONITIS AS A FORM OF CLINICAL PRESENTATION OF LISTERIOSIS

\begin{abstract}
RESUMEN
Las infecciones por gérmenes del género Listeria pueden ser esporádicas o en brotes epidémicos y cursar con múltiples formas de presentación clínica. Entre ellas, la listeriosis de origen abdominal es una de las menos frecuentes, especialmente en aquellos individuos sin un compromiso previo del sistema inmune o una enfermedad hepática concurrente.

Presentamos el caso de un varon joven, sano y sin factores predisponentes, con una peritonitis focal causada por Listeria monocytogenes. El paciente fue intervenido de urgencia, practicándose una colectomía derecha y la evacuación de un absceso retroperitoneal. La evolución postoperatoria fue favorable, mediante un tratamiento antibiótico consistente en una pauta de amoxicilina y ácido clavulánico durante tres semanas.

En la discusión, se analizan los diversos aspectos epidemiológicos, clínicos y terapéuticos de la listeriosis, con una especial atención por los episodios infectivos abdominales.
\end{abstract}

PALABRAS CLAVE: Infecciones por Listeria. Listeria monocytogenes. Peritonitis. Laparotomía. Absceso abdominal. Colectomía. Técnicas y procedimientos de laboratorio. Agentes antibacterianos.

\begin{abstract}
Infections by germs of Listeria genus can occur sporadically or in epidemic outbreaks and have different clinical presentations. Abdominal origin is very unusual among them, especially in no immunocompromised patients or without concurrent liver illness.

We present a young healthy man who is lacking in underlying diseases, suffering from focal peritonitis caused by Listeria monocytogenes. The patient had to be operated on, requiring immediate colectomy and evacuation of a retroperitoneal abscess. The postoperative evolution was favorable under antibiotic treatment with amoxicillin and clavulanic acid during 3 weeks.

The clinical-epidemiological and therapeutic aspects of listeriosis are analysed in the discussion, giving special attention to abdominal infective episodes.
\end{abstract}

KEY WORDS: Listeria infections. Listeria monocytogenes. Peritonitis. Laparotomy. Abdominal abscess. Colectomy. Laboratory techniques and procedures. Anti-bacterial agents.

Sánchez Beorlegui J, García Sánchez S. Peritonitis focal como forma de presentación clínica de una listeriosis. An Med Interna (Madrid) 2005; 22: 335-338.

\section{INTRODUCCIÓN}

Dentro del género Listeria se agrupan diversas especies de cocobacilos gram-positivos, anaerobios facultativos, aunque tan solo una variedad, Listeria monocitógenes (LM), afecta al ser humano (1). LM se considera un patógeno para el hombre desde hace unos 50 años. Las pocas infecciones detectadas correspondían, típicamente, con meningitis o sepsis en embarazadas, neonatos o pacientes con trastornos de la inmunidad. Sin embargo, el número de casos diagnosticados ha aumentado de forma progresiva en los dos últimos decenios y, paralelamente, se han documentado cambios importantes la inciden- cia, la epidemiología y la clínica del microorganismo. Dichas modificaciones pueden resumirse en tres puntos, que explican la relevancia de LM en la literatura científica reciente $(2,3)$ :

-Aumento del número total de infecciones.

- Aumento de la incidencia en el adulto y, en particular, en el adulto sano e inmunocompetente. El porcentaje de casos en individuos sin antecedentes patológicos oscila, actualmente, en torno al 30-40\% (4).

-Aumento del porcentaje de episodios infectivos que cursan con formas atípicas de presentación clínica.

En el presente artículo presentamos un caso que refleja estas modificaciones: el de un varón joven y sin factores de

Trabajo aceptado: 22 de febrero de 2005 
riesgo que acude a urgencias hospitalarias con un cuadro de dolor abdominal y fiebre, al que se interviene de urgencias bajo la sospecha de una peritonitis de origen apendicular. En la discusión pondremos al día los conocimientos sobre LM, y la situación que ocupa dentro de la patología infecciosa, además de actualizar las vías de investigación que se siguen en estos momentos.

\section{CASO APORTADO}

Paciente varón de 21 años de edad, soldado profesional, sin antecedentes médicos o quirúrgicos de interés que acudió a urgencias de nuestro Hospital, remitido por el médico militar, relatando un cuadro molestias abdominales inespecíficas de varios días de evolución. El enfermo se encontraba realizando unas maniobras de supervivencia en la montaña. Desde hacía 18 horas el dolor, inicialmente difuso, se había focalizado en la fosa ilíaca derecha (FID) y aumentado su intensidad. Presentaba anorexia progresiva, sin alteraciones del tránsito gastrointestinal. La exploración mostraba un abdomen blando y depresible, muy doloroso a la presión profunda en FID con defensa y reacción peritoneal acusada. La temperatura axilar era de $38,5^{\circ}$, sin otros hallazgos reseñables. Los estudios radiológicos de tórax y abdomen no reflejaban patología. Analítica: leucocitos, 14.000 x 109 /1 (78\% neutrófilos); hemoglobina, $14,46 \mathrm{mg} / \mathrm{dl}$; plaquetas, 268.000 x 109 /1. Resto, incluyendo química clínica, función hepática y estudio de coagulación: normal. La ecografía abdominal mostraba una intensa meteorización del intestino delgado que impedía la visualización del ciego y el apéndice vermiforme. No se observaba líquido libre, en cantidad significativa, entre las asas o en el fondo de saco de Douglas.

Se indica una laparotomía exploradora urgente bajo la sospecha de una apendicitis aguda. Se premedica al paciente con amoxicilina y ácido clavulánico 1.000/200 mg intravenosos, respectivamente, unidosis. A través de la incisión de McBurney, se observa una gran tumoración cecal de consistencia dura y múltiples adenopatías. Tras el cierre de la incisión, se aborda de nuevo la cavidad a través de una laparotomía media supra-infraumbilical. La masa, con el aspecto de una perityphilitis, englobaba ciego, apéndice e íleon terminal (Fig. 1). Se visualizaban y palpaban ganglios mesocólicos. En el retroperitoneo, en contacto con la gotiera parietocólica derecha, se drenó un absceso de pus cremoso, blanquecino e inodoro que contenía unos 100 ó 150 cc (Fig. 1). Se tomaron muestras que fueron cultivadas en tioglicolato, agar sangre y agar chocolate y, posteriormente, analizadas mediante un sistema BACTEC $9240^{\circledR}$.

Ante las dudas sobre el origen canceroso de la tumoración, se practicó una hemicolectomía derecha reglada, con intención oncológica, resecando en la pieza quirúrgica el peritoneo parietal afecto y todas las adenopatías palpables. La reconstrucción del tránsito digestivo se llevó a cabo mediante una anastomosis íleo-cólica latero-lateral manual.

En postoperatorio inmediato, el enfermo presentó un pico febril vespertino, con temperatura superior a $38,5^{\circ}$. Se extrajeron hemocultivos que resultaron ser microbiológicamente estériles. En el quinto día del postoperatorio se nos informa del crecimiento en el cultivo de la muestra de líquido biológico de un bacilo gram positivo del género Listeria spp. A través de las técnicas habituales de laboratorio y del serotipado, mediante el método de aglutinación, el patógeno fue identificado, definitivamente, como una Listeria de la especie monocytoges perteneciente al serotipo $4 \mathrm{~b}$. En el antibiograma el germen era sensible a la ampicilina, cefotaxima, vancomicina, rifampicina, eritromicina, cotrimoxazol, ciprofloxacina y amoxicilina más ácido clavulánico. Dada la buena evolución clínica del paciente, con desaparición de la fiebre, se mantuvo la pauta antibiótica, consistente en 3.000/600 mg de amoxicilina y ácido clavulánico, respectivamente, repartidos en tres dosis intravenosas diarias. En el sexto día se inicia y progresa la tolerancia a la alimentación por vía oral, con resul-
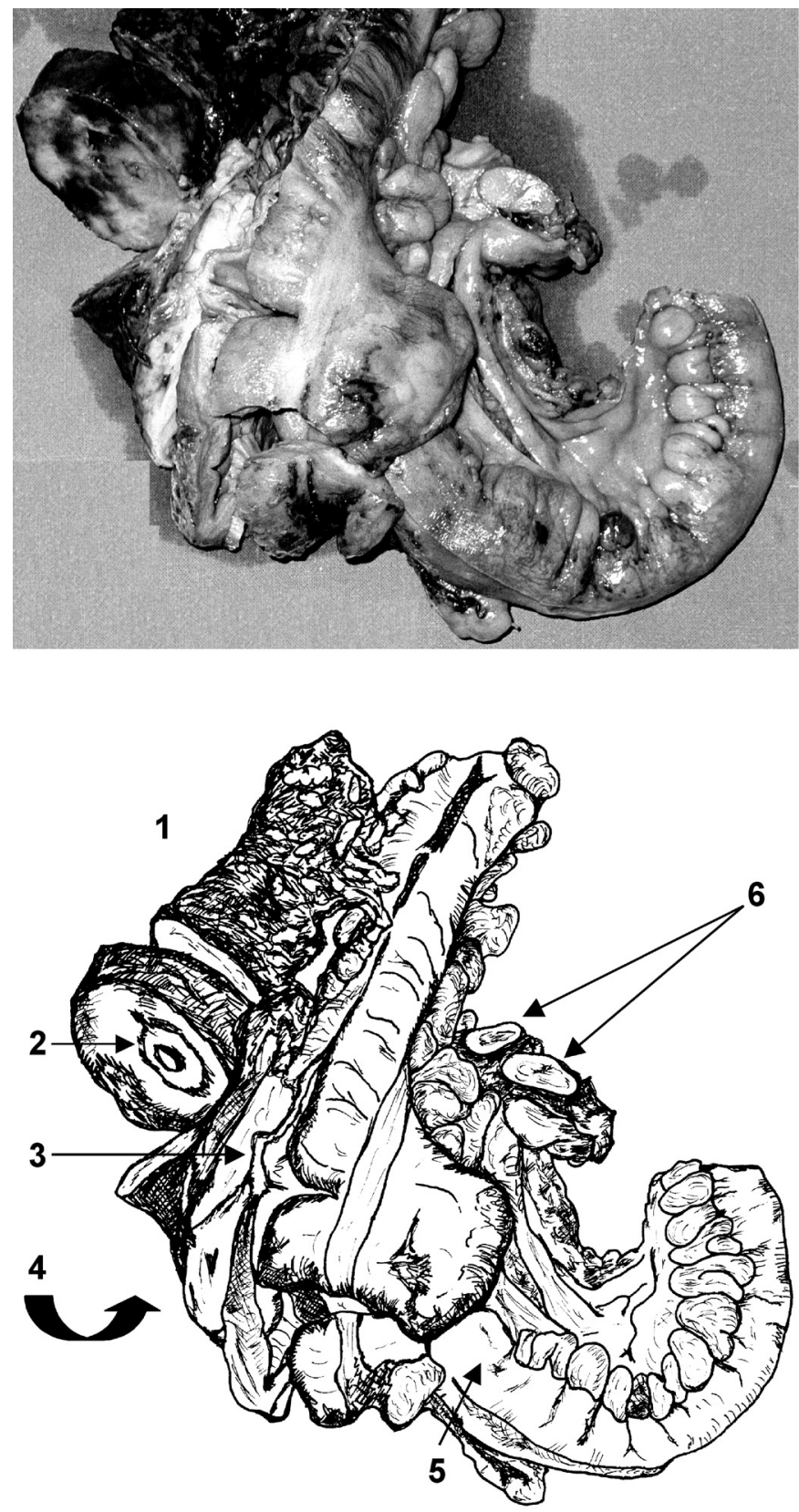

Fig. 1. Fotografía e interpretación artística de los hallazgos macroscópicos intraoperatorios. Pieza de resección quirúrgica que incluye íleon terminal, ciego, con apéndice cecal, colon ascendente y meso: Se observa una masa con aspecto de una perityphilitis (1) que englobaba por completo el apéndice (2) y parcialmente el ciego, cuya pared externa se muestra engrosada (3). La incisión peritoneal permitió drenar un absceso en retroperitoneo frío, del que se tomaron muestras para su cultivo y posterior análisis microbiológico (4). El íleon terminal no estaba afectado (5), pero se palpaban gruesas adenopatías en los mesos intestinales (6).

tados positivos. En el día catorce del postoperatorio, como medida previa al alta, se suspende la antibioterapia intravenosa y se sustituye por una pauta oral de $1.500 / 375 \mathrm{mg}$ de amoxicilina y ácido clavulánico cada 24 horas, fraccionada en tres dosis, que se mantuvo durante una semana más. El paciente recibe el alta hospitalaria tres días después.

$\mathrm{Al}$ año de la intervención el enfermo se encontraba asintomático y desarrollando una actividad normal. Se solicitó una analítica com- 
pleta, colonoscopia y TAC de abdomen en los que no se informaron hallazgos patológicos o sugerentes de enfermedad inflamatoria intestinal.

\section{DISCUSIÓN}

El término genérico de listeriosis define cualquier infección en el hombre causada por LM, con independencia de su forma de presentación.

Hace unas décadas, se describían listeriosis esporádicas, publicadas como casos únicos o agrupados en series cortas, recogidas durante un largo periodo de tiempo. Más recientemente (últimos 20 años), junto al incremento del número de infecciones, han comenzado a describirse, cada vez con mayor frecuencia, brotes epidémicos extra e intrahospitalarios. Como consecuencia, la listeriosis paso a considerarse, en los EE.UU., una enfermedad emergente dentro del grupo de las toxiinfecciones alimentarias (5), aplicándose una política de tolerancia cero en los controles sanitarios de la cadena alimenticia (6).

Las manifestaciones clínicas más frecuentes son una meningoencefalitis, una sepsis sin focalidad aparente o una enfermedad de tipo gripal "inespecífica" en pacientes inmunodeprimidos (trasplantados, cirróticos, alcohólicos, SIDA, oncológicos, etc.), neonatos o gestantes. Otras presentaciones atípicas, pero ahora en franca expansión, pueden ser abscesos localizados, peritonitis, neumonía, pleuritis, endocarditis, osteomielitis, colecistitis, endoftalmitis, lesiones cutáneas, conjuntivitis, uretritis, hepatitis, artritis séptica, etc. (2,3). En los casos de corta evolución predomina la formación de abscesos que en las formas subagudas (hasta un 25\%) o cronificadas se convierten en granulomas (3).

El diagnóstico de listeriosis requiere el aislamiento del germen en un material biológico obtenido de las zonas afectadas (pus, tejidos, placenta, etc.) o en el cultivo de muestras que se presumen estériles como líquido cefalorraquídeo, fluido peritoneal, sangre, meconio, etc. (4). Las recientes tecnologías de laboratorio han permitido comprobar que LM es un germen ubicuo, que coloniza diversas fuentes de origen animal y vegetal (1). Puede ser detectado en infinidad de alimentos frescos y en el tubo digestivo de sujetos asintomáticos, que jamás desarrollarán enfermedad alguna. Estas técnicas avanzadas, son capaces de ofrecer un perfecto diagnóstico diferencial microbiológico (por ejemplo, con difteroides, haemophilus, enterobacterias, streptococos betahemolíticos), inalcanzable para las pruebas diagnósticas básicas, como la tinción de gram (7). Su elevado coste las hace inviables para los sistemas sanitarios de países en vías de desarrollo, en los que una infección por LM continúa siendo, hoy en día, un diagnóstico excepcional (8).

En las formas epidémicas de listeriosis, la puerta de entrada suele ser el tracto gastrointestinal, siendo LM vehiculizado por una fuente alimentaria común (7). Pese a la posibilidad de que los brotes se produzcan en hospitales, la listeriosis no se considera una enfermedad nosocomial (3). Sin embargo, en la mayoría de los casos esporádicos, con la excepción de las sepsis neonatales (contaminación placentaria o en el canal del parto), resulta imposible identificar el origen infectivo y el mecanismo de transmisión $(3,6,7)$. La importancia y el auténtico el papel que desempeña el portador intestinal sano en la epidemiología de la enfermedad (aproximadamente un 5\% de la población) se discute actualmente, así como la posibilidad de que puedan producirse inoculaciones cruzadas con una transmisión de hombre a hombre, similar al contagio directo que experimentan carniceros, matarifes o veterinarios a partir de animales infectados $(3,6)$.

Las peritonitis por LM son una forma de presentación poco habitual. El microorganismo se detecta en el intestino de un porcentaje significativo de la población y es posible que una respuesta inmunitaria disminuida favorezca el desencadenamiento de los mecanismos infecciosos $(6,9)$. Pacientes cirróticos (ascitis), trasplantados hepáticos, individuos con enfermedad inflamatoria intestinal, entre otros, son los más afectados por cuadros abdominales de listeriosis.

La forma típica de infección peritoneal por LM es una peritonitis bacteriana espontánea (PBE) por contaminación del líquido ascítico en enfermos hepáticos. El cuadro, sumamente grave, cursa con elevada mortalidad (10). También se han descrito adenitis mesentéricas, plastrones inflamatorios y abscesos localizados por perforación del tubo digestivo (9,11). En estos pacientes, la cirugía urgente o diferida puede estar indicada (9). En un tercio de las ocasiones, un cuadro de gastroenterocolitis febril precede en algunos días al inicio clínico de la listeriosis abdominal $(6,7)$.

No se ha demostrado de forma concluyente si la afectación del abdomen se produce secundariamente, tras un episodio previo de diseminación hematógena, o bien, si el propio germen puede atravesar la pared del intestino $(4,12,13)$. En las peritonitis por perforación cólica, LM ha podido ser aislada en las perforaciones, vasos sanguíneos y en la submucosa, aunque no en el epitelio sano $(1,13)$.

El tratamiento ideal de la listeriosis es la Ampicilina a dosis elevada, sola o asociada con un aminoglucósido (Gentamicina) cuando se presenta en su forma séptica. Esta sinergia es la más potente en los estudios in vitro y la que cuenta con un consenso más amplio como tratamiento de elección (4). El

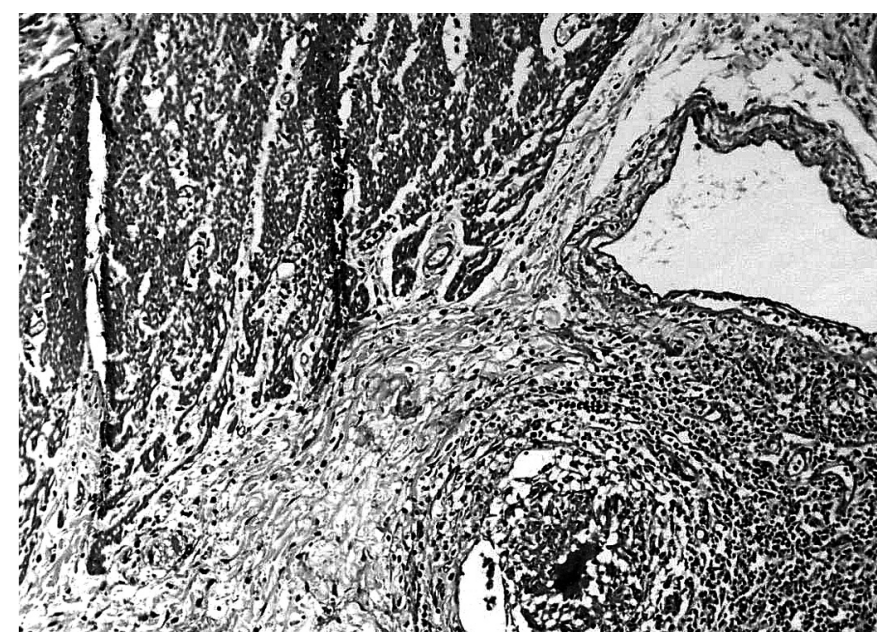

Fig. 2. Anatomía patológica. Submucosa intestinal y apendicular: Infiltrados inflamatorios con formación de granulomas constituidos por histiocitos epitelioides y células gigantes multinucleadas de tipo Langhans, rodeados por un collar de fibroblastos y linfocitos. En algunos granulomas se observa necrosis central. Junto con los granulomas, un infiltrado inflamatorio afecta a la pared intestinal y apendicular, constituido por linfocitos, células plasmáticas, histiocitos, eosinófilos y polimorfonucleares neutrófilos, a su vez con diversos focos necróticos. 
tratamiento debe ser mantenido al menos durante dos semanas.

El caso aquí presentado es un buen compendio de las peculiaridades propias de la listeriosis abdominal atípica, entendiendo por esta a todas las formas de presentación distintas de la PBE. Entre ellas, la existencia de un prodromos de gastroenterocolitis, la tendencia a formar granulomas, la afectación predominante de la submucosa intestinal (Fig. 2) y un diagnóstico diferido, basado en técnicas avanzadas de laboratorio y microbiología. Por último, reseñar que la revisión de las incidencias anotadas por el médico militar durante esas maniobras no permitieron descartar o confirmar un brote epidémico de listeriosis.

\section{Bibliografía}

1. Chiba M, Fukushima T, Koganei K, Nakamura N, Masamune O. Listeria monocytogenes in the colon in a case of fulminant ulcerative colitis. Scand J Gastroenterol 1998; 33: 778-82.

2. Ferrer D, Gómez D, Diosdado N, Rafecas FJ. Listeriosis en el adulto. presentación de 14 casos. Enf Infec Microbiol Clin 1989; 7: 424-7.

3. Hernández A, Almirante B, Pahissa A, Capdevila JA, Planes AM, Gasser I et al. Listeriosis en el adulto. Consideraciones clínicas, epidemiológicas y terapéuticas basadas en una serie de 26 casos. Enf Infec Microbiol Clin 1990; 8: 414-9.

4. Gellin BG, Broome CV. Listeriosis. JAMA 1989; 261: 1313-20.

5. Shallow S, Daily P, Rothrock G, Reingold A, Vugia D, Warterman S, et al. Foodborne diseases active surveillance network, 1996. Morb Mortal Wkly Rep 1997; 46: 258-61.

6. Donnelly CW: Listeria Monocytogenes. A continuing challenge. Nutrition Rev 2001; 59: 183-94.

7. Dalton CB, Austin CC, Sobel J, Hayes PS, Bibb WF, Graves LM, et al. An outbreak of gastroenteritis and fever due to Listeria monocytogenes in milk. N Engl J Med 1997; 336: 100-5.
Como conclusión, destacaremos que en los países desarrollados LM ya no debe ser considerado como un patógeno extraordinario para el hombre. La frecuencia con que se diagnostica la listeriosis aumenta de forma paralela a los medios técnicos implementados en los laboratorios. El facultativo debe tener presente que los mecanismos de transmisión del germen y las formas de presentación clínica son múltiples, tanto en los casos aislados como en los brotes epidémicos. Con esas premisas, un diagnóstico precoz y un tratamiento acertado permitirán disminuir unos porcentajes de mortalidad que continúan registrando porcentajes elevados, muy especialmente en los enfermos inmunosuprimidos.

8. Crespo MP, Vélez JD, Castañeda C, Hoyos F, López ML, Salazar JC Aislamiento de Listeria Monocytogenes en un hospital de tercer nivel. Colombia Med 1999; 30: 89-98.

9. Arias Miranda IM, Nuño Mateo FJ, Noval Menéndez J, Fonseca Aizpuru EM, Menéndez Calderón MJ. Listeriosis en el adulto. Revisión de 10 casos. An Med Interna (Madrid) 2004; 21: 75-8.

10. Nolla-Salas J, Almela M, Gasser I, Latorre C, Salvadó M, Coll P. Spontaneous Listeria monocytogenes peritonitis: A population-based study of 13 cases collected in Spain. Am J Gastroenterol 2002; 97: 1507-11.

11. Sile H, Norwood J. Intra-abdominal abscess caused by Listeria monocytogenes in a patient with acquired hemolityc anemia and thrombocytopenia. South Med J 2002; 95: 1350-2.

12. Sivalingam JJ, Martin P, Fraimow HS, Yarze JC, Friedman LS. Listeria monocytogenes peritonitis: Case report and literature review. Am J Gastroenterol 1992; 87: 1839-45.

13. Jover Díaz F, Laveda Cano R, Martínez Egea A, Coronas Planas M Listeria monocytogenes y colitis ulcerosa. Rev Clin Esp 2002; 202: 123-5. 